\title{
Microwave photonic radar warning receiver: airborne antenna over fiber optic
}

\author{
Receptor de alerta radar fotônico de micro-ondas: antena aerotransportada
} em fibra óptica

Paulo Henrique Kiohara Acyoli Bastos, ${ }^{1,}$, Felipe Streitenberger Ivo ${ }^{1}$, Olympio Lucchini Coutinho

\begin{abstract}
Electronic warfare had great importance mainly in the Second World War. Radar was one of the greatest inventions in the area at that time, reinventing the way war was viewed until then. Nowadays, modern combat aircraft has sophisticated warfare systems. One of them is known as radar warning receiver (RWR), responsible for alerting pilots to possible radar detection and guiding the direction in which it is being radiated. Technological innovations allowed the interaction of the microwave and optoelectronics area, leading to an area known as microwave photonics (MWP). This article presents a photonic link to replace the copper cables used by RWR systems, applying photonic technology in order to improve performance and benefit from the intrinsic characteristics that optical fiber offers to the system, offering a totally passive remote system, in which only one phase modulator is connected to the RWR antenna. The results obtained for a totally photonic link by experiment were satisfactory. As expected, a gain above the unit was obtained. However, the observed noise figure was higher than expected, which ended up resulting in a lower signal noise ratio.
\end{abstract}

Keywords: Electronic warfare, Microwave photonics, Radar warning receiver.

\section{RESUMO}

A guerra eletrônica teve grande importância principalmente durante a Segunda Guerra Mundial. O radar foi uma das maiores invenções da área naquela época, reinventando a forma como a guerra era vista até então. Hoje em dia, as modernas aeronaves de combate possuem sofisticados sistemas de guerra. Um deles é conhecido como receptor de alerta de radar (RWR), responsável por alertar os pilotos para uma possível detecção radar e orientar a direção em que ele se encontra sendo irradiado. As inovações tecnológicas permitiram a interação da área de microondas e optoeletrônica, levando a uma área conhecida como Fotônica de microondas (MWP). Este artigo apresenta um link fotônico para substituir os cabos de cobre utilizados pelos sistemas RWR, aplicando a tecnologia fotônica a fim de melhorar o desempenho e se beneficiar das características intrínsecas que a fibra ótica oferece ao sistema, oferecendo um sistema remoto totalmente passivo, no qual apenas um modulador de fase é conectado à antena RWR. Os resultados obtidos para um sistema totalmente fotônico nos experimentos foram satisfatórios. Como esperado, foi obtido um ganho acima da unidade. Entretanto, a figura de ruído observada foi maior do que o esperado, o que acabou resultando em uma menor relação sinal ruido.

Palavras-chave: Guerra Eletrônica, Fotônica de microondas, Receptor de alerta radar. 


\section{INTRODUCTION}

The concept of electronic warfare (EW) started with technological developments in the areas of communication and detection, mainly during and after the Second World War1. By definition, EW is divided in three areas: electronic attack, electronic protection and electronic support. Electronic attack basically involves deceiving and obstructing enemy communication radars. Electronic protection consists of limit electromagnetic signatures and protects military equipment from enemy electronic attacks. The electronic support has the functions of detecting radar emissions, locating and classifying them as friends or enemies and supplying that information to other EW systems, aircraft crew, as well as commanding and controlling intelligence services ${ }^{1,2}$.

One system used as EW support in modern fighters is the radar warning receiver (RWR). It is responsible for detecting and characterizing radar emissions and alerting the pilot when the aircraft is under detection ${ }^{3,4}$. This system has a set of antennas placed at strategic positions around the aircraft to get a wide coverage and to perform direction finding of the emission. EW systems usually operate at frequency bandwidth from 0.5 to $40 \mathrm{GHz}$, to detect radar pulses normally used in weaponry systems4. However, to achieve these functionalities, the antennas are often placed at positions in which it is difficult to launch coaxial cables and waveguides, as well as electric power supply wires.

Microwave photonics (MWP) show up as a good solution to overcome these limitations, having as advantages: low electromagnetic propagations losses, low weight, small size and easy handle characteristics of fiber optic systems.

MWP aggregate two areas of knowledge: microwave engineering and optoelectronics. Initially, MWP was driven by telecommunication companies, reaching levels of performance sufficient to draw the attention of military applications ${ }^{5}$. MWP incorporate a series of photonic techniques into microwave engineering ${ }^{6}$, improving the performance of communication systems and networks. MWP system can deliver relevant improvements in dynamic range, signal-to-noise ratio and bandwidth, among other advantages, like electromagnetic immunity ${ }^{7,8}$. The use of this promising technology to transmit and to process radiofrequency (RF) signal over fiber has gained attention on civil and military application, such as EW systems.

The main objective of this article was, through mathematic analysis and experiments, to demonstrate the concept of MWP into an airborne RWR system, proposing an all-fiber optic solution for the receiving antennas system, in substitution to coaxial cables transmission lines. The principle of operation of a phase-to-intensity RF over fiber link is presented ahead, as well as the experimental proof of the concept, and the EW application test.

\section{PRINCIPLE OF OPERATION}

\section{Phase-to-intensity modulation conversion microwave photonic link}

Fig. 1 shows the schematic diagram of the photonic link. The part called central station unit is in which most photonic devices are located, leaving only the phase modulator (PM) isolated at the remote antenna probe area. Then, only the modulator and the RWR antenna will be positioned outside the controlled area.

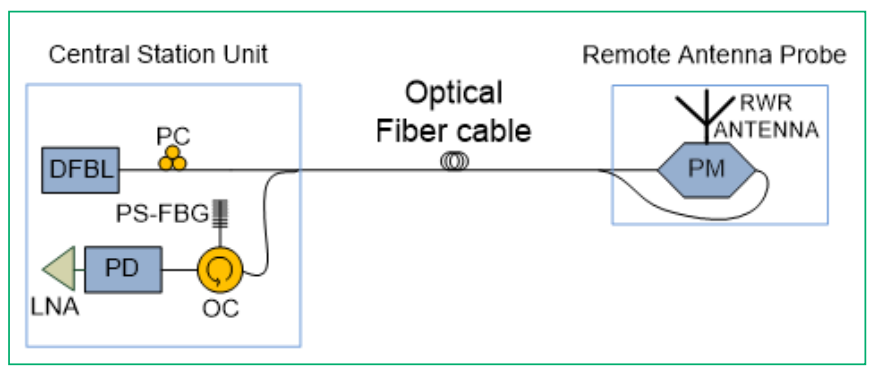

Figure 1: Architecture of the proposed photonic link.

DFBL: distributed feedback laser; PD: photodetector; PC: polarization controller; PS-FBG: phase shift fiber Bragg grating; LNA: low noise amplifier; OC: optical circulator; RWR: radar warning receiver; PM: phase modulator.

A distributed feedback laser (DFBL) with a wavelength of $1,551 \mathrm{~nm}$ is used, providing light as an optical carrier at the input of the $\mathrm{PM}$, in which the RF signal received by the antenna is then modulated. A polarization controller (PC) is used between the laser and the modulator, ensuring greater efficiency, since the PM is sensitive to polarization.

In Fig. $2 \mathrm{a}, \Gamma_{\mathrm{c}}$ and $\Gamma_{0}$ are the reflectivity values given in $\mathrm{dB}, \Gamma_{\mathrm{c}}$ is the notch value and $\Gamma_{0}$ the PS-FBG filter arms. $\Gamma_{0}$ also represents optical losses, in this case by reflection, as part of the light is still transmitted.

The modulated signal then passes through an optical circulator (OC), in which the signal is directed to the phase shift fiber Bragg grating (PS-FBG), leading it to the process of converting phase to intensity modulation (PM-IM). In addition, this PS-FBG can be used as a tunable microwave photonic filter (MPF) (Fig. 2b) with ultra-fast tuning ${ }^{8,9}$. 




Figure 2: Operating principle of the PS-FBG used for PM-IM conversion and used as a photonic filter. PS-FBG: phase shift fiber Bragg grating; PM-IM: phase to intensity modulation; MPF: microwave photonic filter; RF: radiofrequency.

The PM-IM conversion process is necessary since the photodetectors (PD) are only sensitive to variations in optical intensity. In the PM, the beats between the sideband and carrier are canceled, because they are out of phase ${ }^{10}$. When one of the first order sidebands enters the region known as notch of the PS-FBG, the amplitude and the phase of this sideband are changed, and the PMIM conversion happens ${ }^{11}$.

After the PM-IM conversion, the signal reflected by the PS-FBG passes through the OC again and it is received by the PD and converted from an optical signal to an electrical signal. A commercial low noise amplifier (LNA) from $0.5 \mathrm{GHz}$ to $18 \mathrm{GHz}$ with $42 \mathrm{~dB}$ of gain and $4 \mathrm{~dB}$ of noise Fig. 3 at $3 \mathrm{GHz}$ is used to compensate the link losses.

The characterization of the used PS-FBG was carried out at the Laboratório de Guerra Eletrônica (LabGE) of the Instituto Tecnológico de Aeronáutica (ITA) and shows that it operates as a MPF with a bandwidth of $154 \mathrm{MHz}^{8,12}$.

\section{Link performance, gain, noise figure and frequency response}

Firstly, we must consider the carrier's optical signal, provided by the laser as expressed by Yariv and Yeh ${ }^{13}$ (Eq. 1):

$$
E(t)=E_{0} e^{j\left(\omega_{0} t\right)}
$$

in which: $\mathrm{E}_{0}=$ the optical carrier amplitude; $\omega_{0}=$ the angular frequency.

The modulating RF signal provided by the antenna is injected into the modulator, as expressed as Eq. $2^{13}$ :

$$
v_{r f}(t)=V_{r f} \cos \left(\omega_{r f} t\right)
$$

in which: $\omega_{r f}=$ the angular frequency of the RF modulating signal; $V_{r f}=$ the amplitude of the RF modulating signal.

After the phase modulation is performed, assuming that the optical carrier with an angular frequency $\omega_{0}$ enters the PM, in which the RF modulating signal expressed by Eq. 2 modulates the light, the electric field at the output of the modulator is given by Eq. $3^{13}$ :

$$
E_{\text {OUT }}(t)=K_{0} E_{0} e^{j\left(\omega_{0} t+\emptyset_{b}\right)} \sum_{n=-\infty}^{n=\infty}(j)^{n} J_{n}(m) e^{-j n\left(\omega_{r f} t\right)}
$$

in which: $K_{0}=$ the optical losses up to the modulator output; $\varnothing_{b}=$ the phase shift of modulated signal; $m=$ the modulation index; $J_{n}=$ the Bessel function of the first kind of order $n$.

In Eq. $4, \mathrm{~m}$ is defined ${ }^{13}$ :

$$
m=\frac{\pi V m}{V \pi}
$$


The PM output signal is injected into the PS-FBG, in which the spectrum symmetry breaks and the PM-IM conversion process occurs. The resulting IM modulated optical signal is then injected into the PD. Then, the electric field at the input of the PD is given by Eq. 5:

$$
E_{p d}(t)=K_{t} E_{0} e^{j\left(\omega_{0} t+\emptyset_{b}\right)} \sum_{n=-\infty}^{n=\infty}(j)^{n} J_{n}(m) \Gamma(\omega) e^{-j n\left(\omega_{r f} t\right)}
$$

in which: $K_{t}=$ all optical losses of the link; $\Gamma(\omega)=$ the frequency response in amplitude of the PS-FBG photonic filter (MPF) described in Fig. $2 \mathrm{~b}$.

The optical losses are mainly related to the connectors, propagation losses and insertion of the devices. To reduce these losses, you can opt for fusion splicing instead of using the connectors. It is also possible to look for optical components with lower insertion losses. However, this would only be necessary if there were a need for the laser to operate at low power.

We can then determine the optical intensity in the PD by the following expression (Eq. 6) ${ }^{8}$ :

$$
I_{d} \propto E_{p d} E_{p d}^{*}
$$

The PD current $I_{d}$ is proportional to the optic intensity. So, the microwave output signal can be recovered at this point. Considering a small signal condition, in which $\mathrm{m}<<1$, the PM-IM photonic link power intrinsic gain $\mathrm{G}$ is expressed by Eq. $7^{8,14}$ :

$$
G=P_{o d}^{2}\left(\frac{\pi \eta}{V \pi}\right)^{2} F_{c}^{2}\left(\frac{Z_{d}}{Z_{d}+Z_{l}}\right)^{2} Z_{m} Z_{l}
$$

in which: $P_{o d}=$ the optical power in the PD already considering all the optical losses of the link; $\eta=$ the responsivity of the PD; $V \pi=$ the half-wave voltage of the modulator; $Z_{d}=$ the PD impedance; $Z_{l}=$ the load impedance; $Z_{m}=$ the impedance of the modulator.

We define $F_{c}$ as the phase to intensity modulation conversion factor (PM-IM), given by Eq. 8:

$$
F_{c}=\left(1-\frac{\sqrt{\Gamma_{0} \Gamma_{c}}}{\Gamma_{0}}\right)
$$

Substituting Eq. 8 for Eq. 7, and considering $\mathrm{G}_{\mathrm{LNA}}$ as the gain of the LNA placed after the PD, we can then calculate the total gain Gt of the system as (Eq. 9):

$$
G_{t}=G_{L N A} P_{o d}^{2}\left(\frac{\pi \eta}{V \pi}\right)^{2}\left(1-\frac{\sqrt{\Gamma_{0} \Gamma_{c}}}{\Gamma_{0}}\right)^{2}\left(\frac{Z_{d}}{Z_{d}+Z_{l}}\right)^{2} Z_{m} Z_{l}
$$

Another important parameter to consider in order to measure the performance of a photonic link is its noise figure ${ }^{14-16}$ :

$$
N F_{L}=10 \log \left[P_{r e}+\frac{2|e| P_{o d} \eta}{K_{b} T G}+\frac{\eta^{2} P_{o d}^{2} \text { rin }}{K_{b} T G}+\frac{1}{G}\right]
$$

in which: $K_{b}=$ the Boltzmann constant; $T=$ the temperature, in Kelvin; $e=$ the electron charge; $P_{o d}=$ the incident optical power in the PD; $\eta=$ the responsivity of the PD; rin = the laser relative intensity noise; $\mathrm{G}=$ the gain of the link without amplification, expressed in Eq. 7 .

The total noise figure (NF) of the link with post amplification is given by Eq. 11:

$$
N F=N F_{L}+10 \log \left[\left(\frac{F_{a}-1}{G}\right)\right]
$$

in which: $F_{a}=$ the amplifier noise factor; $\mathrm{G}=$ the photonic link gain in decimal.

\section{EXPERIMENT}

The experiment was carried out at the LabGE of the ITA. All components used in the experiments were experimentally characterized at the laboratory. Fig. 3 shows all the devices used in the experiment. 


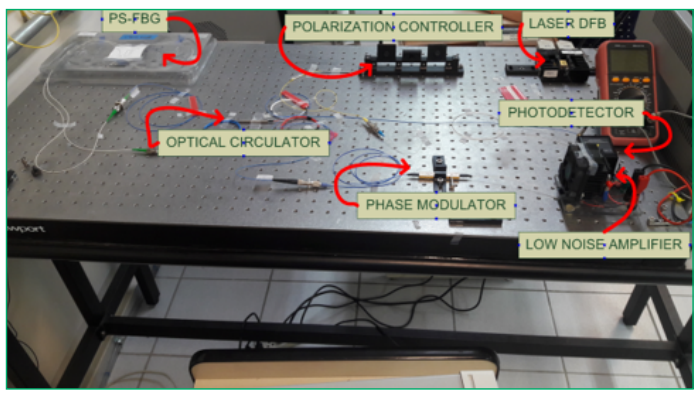

Figure 3: Experimental optical link.

PS-FBG: phase shift fiber Bragg grating; DFB: distributed feedback.

The DFBL delivers a maximum optical power of $100 \mathrm{~mW}$ and was characterized by an optical spectrum analyzer. The used PM was from Covega.

The $\mathrm{V}_{\pi}$ measurement of the PM was obtained adjusting the $\mathrm{RF}$ signal amplitude, $\mathrm{V}_{\mathrm{m}}$, to obtain $\mathrm{J}_{0}=\mathrm{J}_{1}, 1.42$. This value can be acquired directly through the graph of the Bessel functions ${ }^{17}$. The RF power at the modulator output was then measured. Thus, it was obtained a modulation voltage $\mathrm{V}_{\mathrm{m}}$ of $3 \mathrm{~V}$ using Eq. 1. It is possible to obtain the voltage $\mathrm{V} \pi$ of the PM, being the measured $\mathrm{V} \pi 6.67 \mathrm{~V}$. The equipment used to carry out the measurement were an Agilent Technologies E8257D RF generator (bandwidth $250 \mathrm{kHz}$ to $20 \mathrm{GHz}$ ) and a E4407B ESA-E Spectrum Analyzer (bandwidth $9 \mathrm{kHz}$ to $26.5 \mathrm{GHz}$ ).

The used photodetector was from New Focus (bandwidth $25 \mathrm{GHz}$ ), and its maximum incident power was $4.3 \mathrm{~mW}$, with a measured responsivity of $0.56 \mathrm{~A} / \mathrm{W}$.

The schematic diagram of the link and the decomposition of the corresponding optical losses are shown in Fig. 4.

Losses were measured point to point, obtaining a total value of $6.87 \mathrm{~dB}, 0.3 \mathrm{~dB}$ losses come from each connector, to physical contact (PC) to and to angled physical contact (APC) connectors.

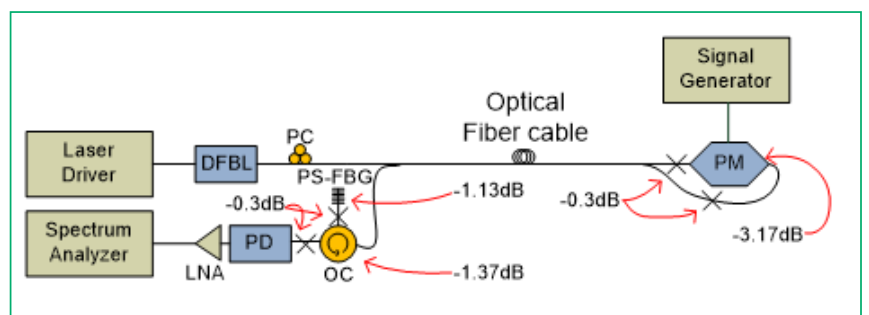

Figure 4: Schematic diagram and losses.

DFBL: distributed feedback laser; PD: photodetector; LNA: low noise amplifier; PC: polarization controller;

PS-FBG: phase shift fiber Bragg grating; OC: optical circulator; PM: phase modulator.

The components shown in Fig. 4 are basically the same as those ones presented in Fig. 1, adding just three essential equipment for measurement: the Thorlabs model ITC 510 laser driver, the Agilent PSG Analog Signal Generator $250 \mathrm{kHz}-20 \mathrm{GHz}$ and the Agilent MXA Signal Analyzer $20 \mathrm{~Hz}-26.5 \mathrm{~Hz}$.

Figure 5 shows the theoretical results disregarding the performances of the MWP link (noise figure and gain), depending on the received optical power at the input of the photodetector.

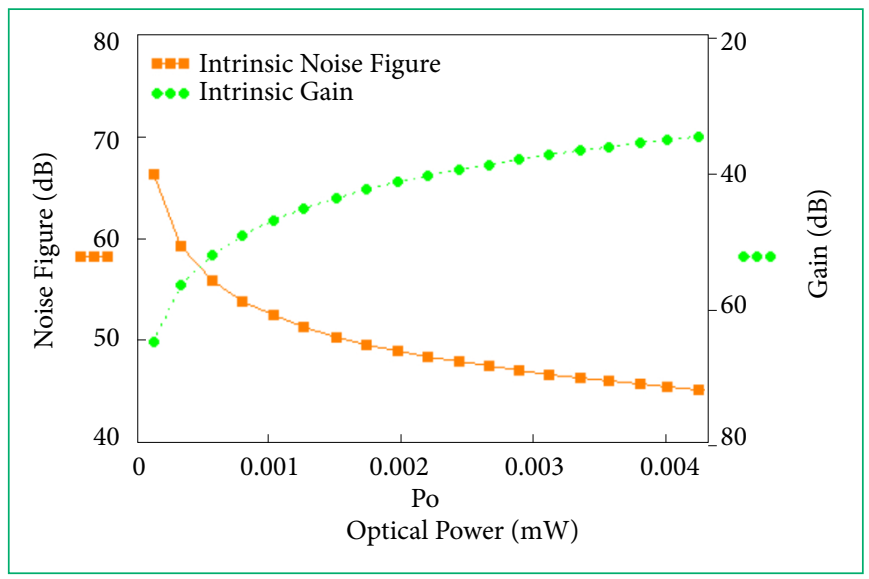

Figure 5: Calculated gain and noise figure. 
The performances of the system were very close to those ones calculated in section "Principle of operation". The measured gain has showed a maximum variation of $0.2 \mathrm{~dB}$ in relation to the calculated one.

The noise figure has presented variations of up to $1.5 \mathrm{~dB}$, mainly due to difficulties with the sensitivity of the equipment for this type of measurement.

The results of the characterization can be seen in Fig. 6, considering the values disregarding the LNA. Figure 7 demonstrates the enhanced gain obtained for the total link $G_{t}$, using a LNA with a gain of $42 \mathrm{~dB}$, with respect to the intrinsic gain of the link.

The maximum value is obtained for $4.3 \mathrm{~mW}$ of incident optical power on the $\mathrm{PD}$ and it is around $-35 \mathrm{~dB}$ of gain, reaching $7 \mathrm{~dB}$ with the LNA use. For the noise figure, we have $42.5 \mathrm{~dB}$, value about $7 \mathrm{~dB}$ higher than the expected ${ }^{14}$.

The system also responded well in frequency. Figure 8 shows the gain in frequency (S21) and reflectivity (S11), considering the amplification of $42 \mathrm{~dB}$ of the LNA too; the measurements were performed between $500 \mathrm{MHz}$ and $3 \mathrm{GHz}$.

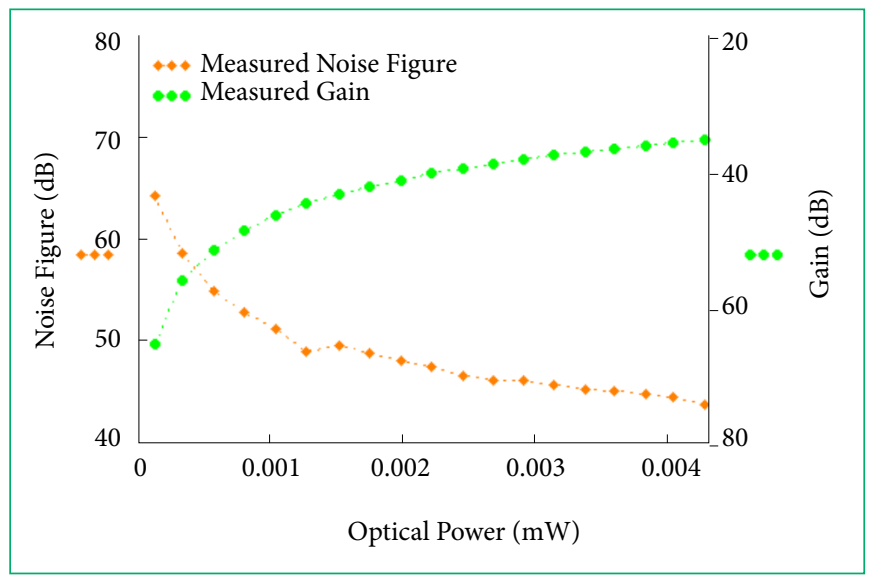

Figure 6: Measured noise figure and gain.

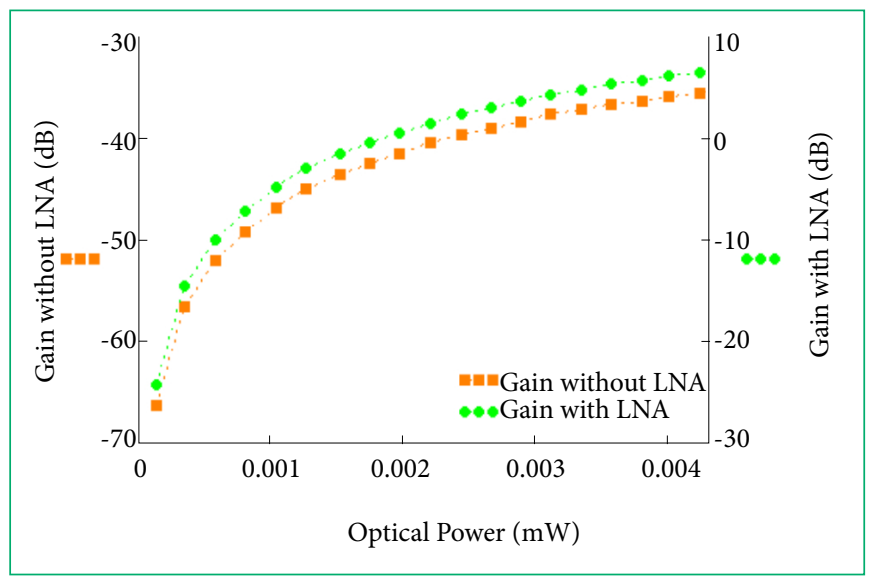

Figure 7: Gain with and without LNA.

LNA: low noise amplifier.

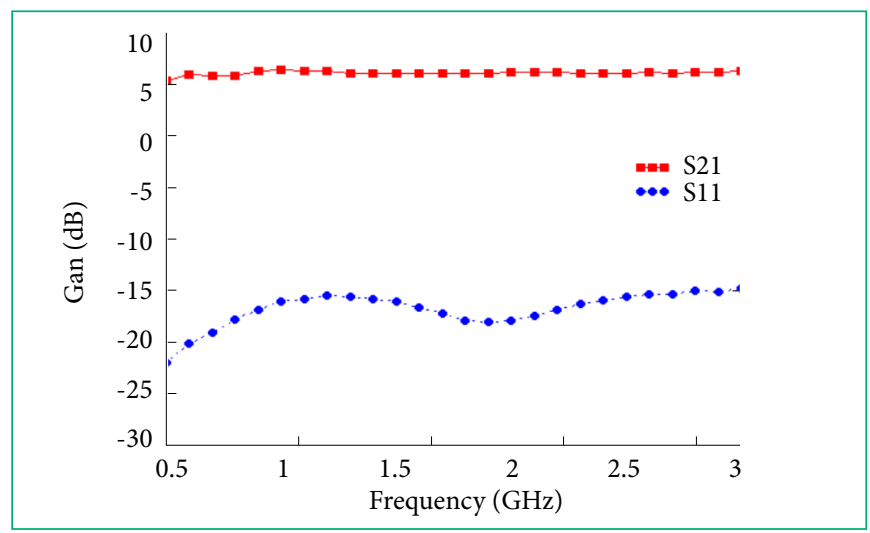

Figure 8: Link frequency response. 


\section{APPLICATION}

Figure 9 shows an example of the distribution of RWR antennas on the aircraft. Once the signal is detected by the RWR antenna, it is transmitted to the central station unit (CSU) to be processed, identifying and giving the exact direction of emission ${ }^{3}$.

The antennas of the RWR system are positioned in strategic places on the aircraft, playing an essential part of the system ${ }^{3}$. Usually, coaxial cables are used to transport the radar signals from the RWR antennas to the CSU. However, coaxial cables are susceptible to electromagnetic interference, which is also one of the major problems faced by RWR systems ${ }^{3}$.

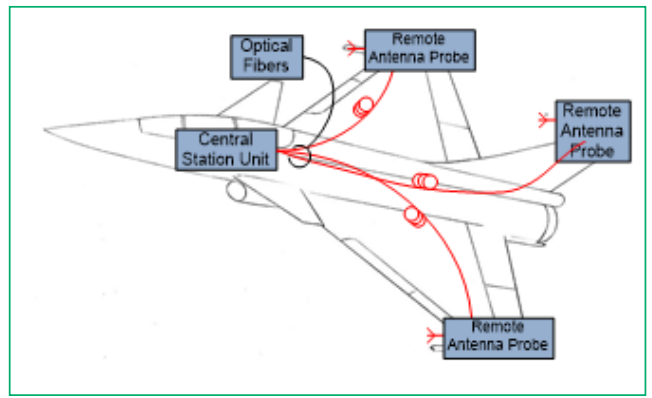

Figure 9: Simplified radar warning receiver system.

The use of optical fibers produces performance improvements and compatible response with the RWR system and adds new functionalities that would not be possible by a conventional electronic system ${ }^{18}$. So, the opportunity to benefit from one of the main intrinsic characteristics of optical fiber systems, which is their electromagnetic immunity, is of great importance here for airborne applications.

Some tests were carried out in an appropriate environment at the LabGE-ITA, to verify the possibility of using this system in a real application of an airborne RWR antenna.

The proposed experiment is the replacement of coaxial cables by optical fibers and the positioning of the PM directly at the output of the RWR antenna. Thus, it creates a totally photonic transmission medium, with the additional interest to be a fully passive system, not requiring feeding power in this case. Figure 10 shows the experiment configuration of transmitting and receiving antennas.

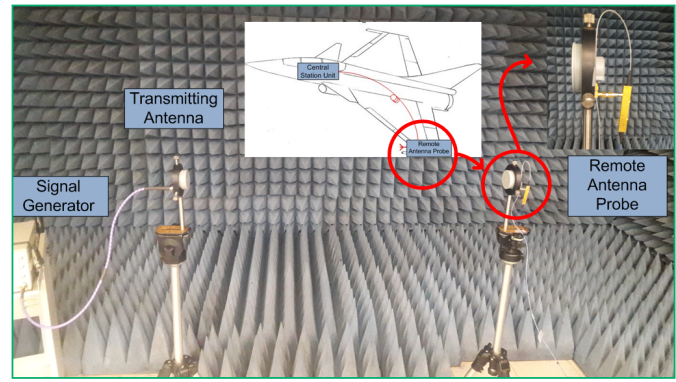

Figure 10: Photonic remote radar warning receiver antenna experiment.

The antenna and the PM set correspond to one of the positions of the aircraft's RWR remote antenna probe. Where the antenna connection with the CSU is totally photonic, the rest of the link remains the same, as in Fig. 4.

The antennas are positioned $1 \mathrm{~m}$ from each other in a suitable place. A pulsed signal with a width of $1 \mu$ s and a period rate of $1 \mathrm{~ms}$ are transmitted by the signal generator. Figure illustrates the pulse with its respective period.

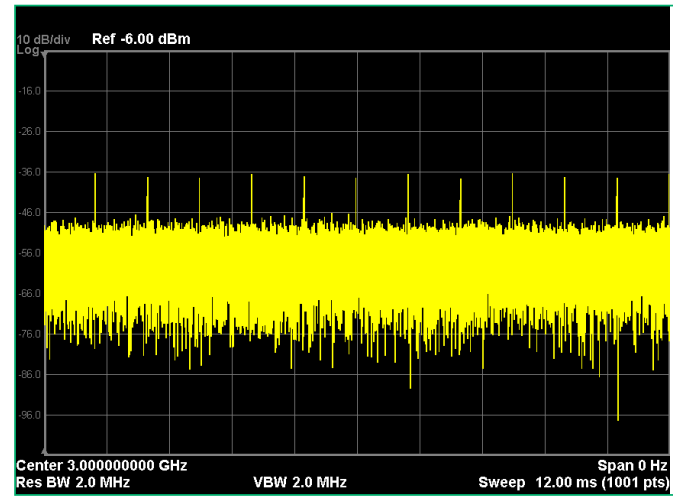

Figure 11: Zero span signal with $1 \mathrm{~ms}$ of period. 
For a pulsed signal with input power of $16 \mathrm{dBm}$ at $3 \mathrm{GHz}$, it was possible to detect an output signal close to $-38 \mathrm{dBm}$, as shown in Fig. 12, by using a $42 \mathrm{~dB}$ gain LNA post amplifier. It is a weak signal compared to that one presented in session "Experiment". It is important to emphasize that both links have the same parameters, and this drop is due to irradiation loss.

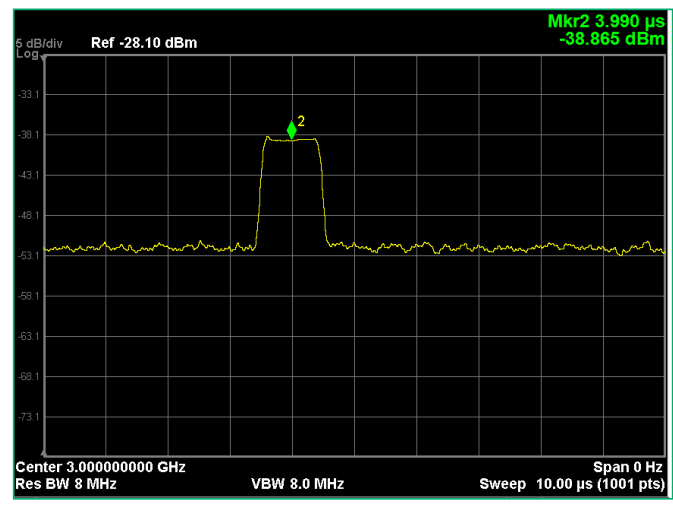

Figure 12: Zero span signal with $1 \mu \mathrm{s}$ width.

Remembering that, analog links to fiber optics offer better performance in relation to noise than conventional ones ${ }^{14}$. However, due to the loss, the signal-to-noise ratio is around $10 \mathrm{~dB}$, that is, the link is operating near its detection limit. It is possible to observe this in the frequency spectrum in Fig. 13.

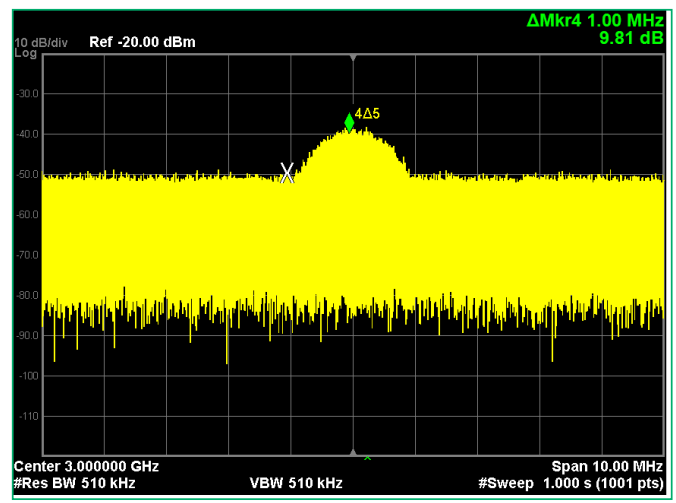

Figure 13: Maximum output power on the spectrum analyzer.

It is important to emphasize that the gain of the MWP link can be optimized by increasing the optical power, but the limitation is mainly in the allowed maximum optical input power of the PD.

According to Friis ${ }^{19}$, the noise of a system depends on the order of the link stages. Bearing this in mind, the use of an LNA as a preamplification would drastically reduce the system noise. However, a feeding medium would be necessary to feed the LNA that would be positioned between the receiving antenna and the electro-optical PM. In order that the system does not lose its proposed characteristic of being totally photonic, a technology called power-over-fiber (PoF) can be used. PoF consists in feeding electronic devices located in remote regions of difficult access or dangerous environments ${ }^{20}$.

\section{DISCUSSION AND CONCLUSIONN}

The results presented in this paper demonstrate the efficiency of the MWP link to transmit with good performance the RWR signal, offering satisfactory results in relation to signal noise and system gain, reaching values close to $10 \mathrm{~dB}$ for the gain of the link with postamplification, and with less than $50 \%$ of the PD's optical capacity.

According to the practical test in section "Application", in spite of the losses due to irradiation, the link presented the expected result, confirming that it is totally possible to use a photonic link to replace the coaxial cables used nowadays in RWR systems. Remembering that, an analog link to fiber optics already offers better values in dynamic range, bandwidth and noise than a conventional RF link. However, a photonic link also offers the intrinsic advantages of the optical fiber when using this technology, such as galvanic isolation, electromagnetic immunity, which in itself already offers an advantage to the system, making it easier to handle, reducing the weight and volume that conventional cables present. 
The low-noise amplifier was used in a post-amplification configuration in order to avoid the need of electric power supply at the remote antenna probe. So, it only compensates the link gain, but not the noise figure. To solve this problem and to reduce the noise figure, we consider now to have a remote LNA at the RWR antenna, and to use the PoF technology to feed $\mathrm{it}^{20}$.

This ongoing research is carried out in cooperation between the MWP research group at the ITA (Brazil) and the photonics research group at the École Nationale d'Ingénieurs de Brest (ENIB, France).

\section{ACKNOWLEDGMENT}

This research is supported by the Conselho Nacional de Desenvolvimento Científico e Tecnológico, the Força Aérea Brasileira and the ENIB, in the framework of a joint research project in MWP between ENIB and ITA (Ref. MWP-ITA-ENIB 2020 Project).

\section{REFERENCES}

1. Gama Neto RB. Guerra cibernética / Guerra eletrônica: conceitos, desafios e espaços de interação. Política Hoje. 2017;26(1):201-17.

2. Congressional Research Service. U.S. Airborne Electronic Attack Programs: Background and Issues for Congress. Congressional Research Service; 2019.

3. Richard W. ELINT The Interception and Analysis of Radar Signals. Boston/London: Artech House; 2006.

4. Filippo N. Introduction to Electronic Defense Systems. $2^{\mathrm{a}}$ ed. Boston/London: Artech House; 2006.

5. Charles H, Edward A. Microwave Photonics: Past, Present and Future. Billerica: IEE; 2008.

6. Carla M. Avanços Recentes em Optoeletrônica Aplicada a Radares e Guerra Eletrônica. São José dos Campos: Departamento de Microondas e Optoeletrônica, Instituto Tecnológico de Aeronáutica; 2009.

7. Capmany J, Novak D. Microwave photonics combines two worlds. Nature. 2007;1:319-30. https://doi.org/10.1038/nphoton.2007.89

8. Felipe I. Filtro de RF Sintonizável Baseado em Processamento Fotônico com Varredura Ultrarrápida. São José dos Campos: Departamento de Eletrônica, Instituto Tecnológico de Aeronáutica; 2018.

9. Capmany J, Mora J, Gasulla I, Sancho J, Lloret J, Sales S. Microwave Photonics Signal Processing. IEEE J Light Technol. 2013;31(4):571-86. https://doi.org/10.1109/JLT.2012.2222348

10. Yariv A, Yeh P. Photonics optical electronics in modern communications. New York: Oxford University; 2007.

11. Li W, Li M, Yao J. A Narrow-Passband and Frequency-Tunable Microwave Photonic Filter Based on Phase-Modulation to Intensity Modulation Conversion Using a Phase-Shifted Fiber Bragg Gratting. IEEE Trans Microw Theory Tech. 2012;60(5):1287-96. https://doi.org/10.1109/ TMTT.2012.2187678

12. Felipe I, Baroni RF, Olympio C. Filtro de RF Fotônico Sintonizável por Variação de Temperatura em Laser DFB. In: Simpósio de Aplicações Operacionais de Defesa, 19., 2017, São José dos Campos. São José dos Campos; 2017.

13. Yariv A, Yeh P. Optical Waves in Crystals. New York: John Wiley \& Sons; 1984.

14. Olympio C. Aplicação de Moduladores Eletroopticos em Enlaces Analógicos a Fibra Óptica. São José dos Campos: Departamento de Eletrônica, Instituto Tecnológico de Aeronáutica; 2005.

15. Olympio C, José O. Enlace analógico a fibra óptica para transmissão de sinais de RF. In: Simpósio de Guerra Eletrônica, 6., 2004, São José dos Campos. São José dos Campos; 2004.

16. Ackerman El, Cox CH. State of Art in Analog Fiber-Optic Link Technology. In: URSI International Symposium on Signals, Systems, and Electronics, 1998. Proceedings. 1998. https://doi.org/10.1109/ISSSE.1998.738100

17. Jerome S, Keith O. An atlas of functions. Washington, D.C.: Hemisphere; 1987.

18. Iezekiel S, Burla M, Klamkin J, Marpaung D, Capmany J. RF engineering meets optoelectronics. IEEE Microw Mag. 2015;16(8):28-45. https:// doi.org/10.1109/MMM.2015.2442932

19. Friis HT. Noise figures of radio receivers. IRE. 1944;32(7):419-22. https://doi.org/10.1109/JRPROC.1944.232049

20. Diouf C, Quintard V, Ghisa L, Guegan M, Pérennou A, Gautier L, et al. Design, characterization, and test of a versatile single-mode power-overfiber and communication system for seafloor observatories. IEEE J Ocean Eng. 2018;45(2):656-64. https://doi.org/10.1109/JOE.2018.2876049 